\title{
Integrated Item Response Theory Modeling of Multiple Patient-Reported Outcomes Assessing Lower Urinary Tract Symptoms Associated with Benign Prostatic Hyperplasia
}

\author{
Yassine Kamal Lyauk, ${ }^{1,2,3,4}$ Trine Meldgaard Lund, ${ }^{2}$ Andrew C. Hooker, ${ }^{3}$ \\ Mats O. Karlsson, ${ }^{3}$ and Daniël M. Jonker ${ }^{1}$
}

Received 4 May 2020; accepted 11 July 2020; published online 29 July 2020

\begin{abstract}
In clinical trials within lower urinary tract symptoms due to benign prostatic hyperplasia (BPH-LUTS), the International Prostate Symptom Score (IPSS) is commonly the primary efficacy outcome while the Quality of Life (QoL) score and the BPH Impact Index (BII) are common secondary efficacy markers. The current study aimed to characterize BPH-LUTS progression using responses to the IPSS, the QoL, and the BII in an integrated item response theory (IRT) framework and assess the Fisher information of each scale. The power of this approach to detect a drug effect was compared with an IRT approach considering only IPSS responses. A unidimensional and a bidimensional pharmacometric IRT model, based on item-level IPSS responses in a clinical trial with 403 patients, were extended by incorporating patients' QoL and summary BII scores over the 6-month trial period. In the developed unidimensional integrated model, the QoL score was found to be the most informative, representing $17 \%$ of the total Fisher information, while the combined information content of the seven IPSS items represented $70.6 \%$. In the bidimensional model, "storage" and both storage and "voiding" disability drove QoL and summary BII responses, respectively. Sample size reduction of $16 \%$ to detect a drug effect at $80 \%$ power was obtained with the unidimensional integrated IRT model compared with its counterpart IPSS IRT model. This study shows that utilizing the information content across the IPSS, QoL, and BII scales in an integrated IRT framework results in a modest but meaningful increase in power to detect a drug effect.
\end{abstract}

KEY WORDS: BPH; BPH Impact Index; Item Response Theory; International Prostate Symptom Score; LUTS; Quality of Life.

\section{INTRODUCTION}

As the prostate enlarges with age, older men may suffer from the obstruction of the prostatic urethra and deterioration of the urethral sphincter function (1). This condition is known as benign prostate hyperplasia (BPH) and is estimated to affect $50 \%$ of the male population by age 60 years $(2,3)$.

Electronic supplementary material The online version of this article (https://doi.org/10.1208/s12248-020-00484-7) contains supplementary material, which is available to authorized users.

${ }^{1}$ Translational Medicine, Ferring Pharmaceuticals A/S, Copenhagen, Denmark.

${ }^{2}$ Department of Drug Design and Pharmacology, University of Copenhagen, Copenhagen, Denmark.

${ }^{3}$ Department of Pharmaceutical Biosciences, Uppsala University, Uppsala, Sweden.

${ }^{4}$ To whom correspondence should be addressed. (e-mail: ysl@ferring.com; yassine.lyauk@sund.ku.dk; yassinekamallyauk@gmail.com; yassine.lyauk@farmbio.uu.se)
Lower urinary tract symptoms (LUTS) often develop due to $\mathrm{BPH}$ and are thought to stem from a combination of both static and dynamic factors of BPH as well as the bladder's response to outflow obstruction $(4,5)$. The prevalence of BPH-LUTS is similar across different countries (6-11) and can hence be considered a medical condition with a substantial impact on public health globally speaking.

To assess BPH-LUTS, which, in addition to urinary function, may impact patients' general well-being as well as different facets of their everyday life, three validated, diseasespecific, patient-reported outcomes (PROs) are conventionally used. The International Prostate Symptom Score (IPSS) (also called as the American Urological Association Symptom index) (12) is the most widely used PRO within BPHLUTS $(13,14)$ and consists of seven items that each can be rated from zero to five. IPSS voiding items describe the severity of a feeling of incomplete emptying of the bladder following urination, urination intermittency, the urgency to urinate, the weakness of the urinary stream, and straining during urination. IPSS storage items describe urination 
frequency, the urgency to urinate, and nocturia (15). Current versions of the IPSS questionnaire include an additional question following the seven IPSS items, known as the Quality of Life (QoL) or "bother" question (16). The QoL question assesses a patient's perception of his current health state by asking how he would feel if he were to spend the rest of his life with his urinary condition. It can be rated from zero to six, zero corresponding to "Delighted" and six to "Terrible." Lastly, the BPH Impact Index (BII) (17) is a four-item questionnaire that assesses the physical discomfort associated with urinary problems, the degree of worrying regarding health due to urinary problems, the perception of overall bother associated with urination, and the hindering of performance of desired activities due to urinary problems. Three of the BII items are rated from zero to three while one is rated from zero to four, resulting in a summary BII ranging from zero to 13 .

In clinical trials investigating treatment of BPH-LUTS, the summary IPSS is conventionally specified as the primary efficacy outcome measure, while the QoL and summary BII are specified as secondary efficacy markers (13). These three scales may contribute different insights into BPH-LUTS, and it may hence be of value to regard the information of these scales jointly rather than separately to more precisely determine the severity of BPH-LUTS in patients. Item Response Theory (IRT) models can be used to incorporate information from multiple PROs to assess the impact of a given disease, giving higher weight to more sensitive PROs, while still capturing information from less sensitive ones. As its name suggests, IRT utilizes the item-level responses in questionnaires to estimate an individual's level of disability (e.g., underlying BPH-LUTS), the sensitivity of each item to change in disability, and the thresholds of item scores along the disability scale. Because IRT uses item-level data and quantifies item sensitivity, an integrated IRT model regarding information from the IPSS, QoL, and BII jointly may allow for a powerful approach for assessing BPH-LUTS and detecting drug effects. IRT analyses combining information from different scales have been performed within the therapeutic areas of neonatal pain $(18,19)$ and migraine (20), but, to date, not within BPH-LUTS.

Building on a recent pharmacometric IRT model based on item-level IPSS data in a clinical trial with the GnRH antagonist degarelix (21), the current study aims to characterize BPH-LUTS progression by joint analysis of item-level IPSS, the QoL score, and BII data in an integrated IRT framework while assessing the informativeness of each scale. The power of this integrated BPH-LUTS IRT model to detect a drug effect will be compared with the longitudinal IRT model considering only IPSS responses.

\section{METHODS}

\section{Data}

Data from Ferring Pharmaceuticals A/S trial CS36 (NCT00947882) was utilized in the current work, which was also used for the development of a previous longitudinal IPSS IRT model (21). CS36 was a Phase II placebo-controlled, double-blind, parallel-group, randomized dose-finding study, where a single subcutaneous injection of either 10,20 , or
$30 \mathrm{mg}$ of the GnRH antagonist degarelix $40 \mathrm{mg} / \mathrm{mL}$ solution was administered to patients. The trial enrolled 403 patients with an IPSS $\geq 13$ and a QoL score $\geq 3$ at the screening visit 2 weeks before dosing at baseline. Over the 6-month trial period, eight visits were planned (a baseline visit and 14 days and 1, 2, 3, 4, 5, and 6 months after dosing). Item-level IPSS and the QoL score were assessed at each of these visits, while the summary BII ( $\left.\mathrm{BII}_{\text {summary }}\right)$ was assessed at three visits (baseline visit and 3 and 6 months after dosing). Due to the unavailability of item-level BII responses, the $\mathrm{BII}_{\text {summary }}$ was considered an item with 14 possible categories.

\section{Item Response Theory Analysis}

Psychometrically, regarding the IPSS as either unidimensional or bidimensional is valid based on multiple studies within BPH-LUTS (21-23). Building on this prior knowledge, both unidimensional and multidimensional integrated IRT approaches were investigated in the current work.

\section{Unidimensional Item Response Theory Modeling}

A unidimensional IRT model was first fit to the data assuming a single latent construct driving patients' responses

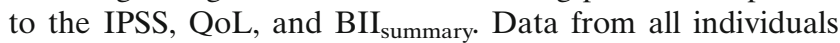
and all visits were used to estimate the item characteristic curves (ICCs) (24-27) (termed the IDVIS approach (21)). The reference baseline latent variable distribution(s) was fixed to standard normal distributions $N(0,1)$, and postbaseline shift parameters were estimated to account for differences in the distribution of latent disability following intervention (placebo or treatment) while assuming that ICCs are constant (24-27).

Each BPH-LUTS measure contains at least six itemresponse categories (zero to five for the IPSS items, zero to six for the QoL score, and zero to 13 for the BII $\mathrm{B}_{\text {summary }}$ item). The probability of a patient answering at least $k$ based on his latent disability was described using a graded response model (28):

$P\left(Y_{i j} \geq k\right)=\frac{e^{a_{j}\left(\psi_{i}-b_{j \cdot k}\right)}}{1+e^{a_{j}\left(\psi_{i}-b_{j \cdot k}\right)}}$

where $a_{j}$ represents the slope/discrimination parameter of item $j, \psi_{i}$ the latent disability of patient $i$, and $b_{j}$ the difficulty/ location parameter of item $j$ for category $k$. Cumulative probabilities for an item with a score of maximum $X$ were modeled as:

$$
\begin{gathered}
P\left(Y_{i j}=0\right)=1-P\left(Y_{i j} \geq 1\right) \\
P\left(Y_{i j}=k\right)=P\left(Y_{i j} \geq k\right)-P\left(Y_{i j} \geq k+1\right) \\
P\left(Y_{i j}=X\right)=P\left(Y_{i j} \geq X\right)
\end{gathered}
$$

where $X$ is five for each of the seven IPSS items, six for the

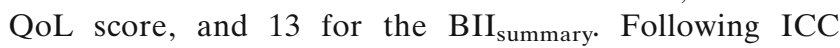
estimation, the original individual assignment was reconciled with the data, and the longitudinal model was combined with the IRT ICC model to describe the relationship between changes in disability over time and response probability. 


\section{Multidimensional Item Response Theory Modeling}

Factor analysis is an established statistical method for informing the item structure of IRT models (29). It aims to explain the correlation between items by assuming that one or more latent variables (factors) steer responses to these items. The factor loadings indicate the covariance between each item and the factor(s) and allow for dimensionality assessment. Factor analysis may be exploratory or confirmatory in nature: the former does not pre-specify the number of factors to explore while the latter does. Building on the bidimensional IRT model that regarded only item-level IPSS (21), the item structure of an integrated multidimensional IRT model was explored through confirmatory factor analysis using two and three dimensions, respectively. Given that a minimum of three items per latent variable is required to preserve IRT model identification, no more than three latent variables were explored in the current analysis. Varimax orthogonal rotation (30) was used as the rotation method during factor analysis. If an item was found to not be predominantly correlated with a single factor, a compensatory graded response model for polytomous data (31) was implemented to allow multiple latent variables to affect the probability of responses for this item. In the compensatory graded response model, the probability of a patient answering at least $k$ for item $j$ is:

$$
\begin{gathered}
P\left(Y_{i j} \geq k\right)=\frac{e^{\left(a_{m, j *} \psi_{m}-B_{k, j}\right)}}{1+e^{\left(a_{m, j *} \psi_{m}-B_{k, j}\right)}} \\
\text { with } a_{m, j} * \psi_{m}=a_{1, j} * \psi_{1}+a_{2, j} * \psi_{2}+\ldots+a_{m, j} * \psi_{m}
\end{gathered}
$$

where $m$ is the number of latent variables, $\psi_{m}$ the vector of latent disability estimates for patient $i, a_{j}$ the item-specific discrimination parameters associated with each latent disability, and $B_{k}$ the overall difficulty of the item response category $k$.

\section{Calculation of Fisher Information Content}

The Fisher information content of each item in the unidimensional integrated IRT model was calculated as minus the expectation of the second derivative of the log-likelihood. The sensitivity of each item over the current study's disability range was visualized through their information functions. Ranking of individual items was performed according to the amount of information they contained relative to the total information. This was achieved by calculating the area under the curve for each item divided by the sum of all areas under the curve. The unidimensional IRT model was used for calculation of Fisher Information content as it allows for comparison of the information content among all included items based on the same common latent scale.

\section{Longitudinal Modeling and Covariate Analysis}

Longitudinal integrated IRT model development was similar to that previously reported for longitudinal IRT modeling based on IPSS data and readers are referred to Lyauk et al. (21) for more details. Briefly, data from patients receiving placebo treatment were first modeled to describe the placebo effect, and subsequently, data from patients that received degarelix were added to the dataset to describe the drug effect. Following structural longitudinal model development, baseline demographics (age, weight, and body mass index), baseline physiological disease-specific measures (total prostate volume, serum testosterone, prostate-specific antigen, average flow rate, flow time including time to maximum flow, maximum urine flow, post-void residual volume, voiding time, and voiding volume), and study site region (North America or Europe) were investigated as covariates. For this purpose, a stepwise search (SCM) at a significance level of 0.01 in the forward inclusion step and 0.001 in the backward elimination step. A multiplicative covariate model was used for all parameters except those where the typical value was expected to be zero or close to zero, such as baseline disability. If this was the case, an additive covariate model was used.

\section{Software}

NONMEM version 7.4.3 with the Laplacian method was used for ICC estimation and longitudinal IRT modeling. PerlSpeaks-NONMEM (32) (PsN) version 4.9.0 was used for simulation-based model diagnostics, and the mirt package version 1.31 in R 3.6.0 (33) was used for factor analyses and to obtain initial estimates for ICC estimation in NONMEM.

\section{Model Evaluation and Diagnostics}

The goodness of fit of the ICCs was assessed using the Empirical Bayes Estimate-based (26), as well as the samplingbased (21), cross-validated generalized additive model (GAM) cubic spline smooth. Longitudinal model selection was based primarily on the change in objective function (OFV) and secondly on assessment of visual predictive checks (VPCs). For nested models, a difference in OFV corresponding to a prespecified significance level $(\alpha=0.05$ for everything but covariate analysis) was assumed statistically significant assuming a $\chi^{2}$ distribution. For non-nested models, the Akaike Information Criterion (AIC) was used. In longitudinal IRT modeling, fixing the ICC parameters to the values obtained in the ICC estimation step while estimating the longitudinal parameters and simultaneously estimating the ICCs and longitudinal parameters, respectively, was investigated in terms of OFV reduction. VPCs were used to assess the adequacy of the developed longitudinal models using 200 samples.

\section{Power Calculations}

Power to detect a drug effect was determined by way of clinical trial simulations with the respective final integrated IRT models. The stochastic simulation and estimation (sse) procedure in Perl-Speaks-NONMEM PsN (32) was used specifying 1000 simulated data sets at four different sample sizes while respecting the treatment to placebo allocation ratio in the original CS36 data set. An initial Monte Carlo Mapped Power (MCMP) procedure (34) informed the determination of the sizes of these four data sets. No missing item responses, as well as no dropout, was assumed in the simulations. A threshold of $3.84(p=0.05)$ was used to 
identify significant reductions in OFV between the respective full (estimating a drug effect) and reduced (not estimating a drug effect) models. Type I error was investigated by simulating 1000 data sets under each sample size from the integrated IRT model with no drug effect. The proportion of subsequent estimations where the drug effect was identified as significant determined the type I error rate.

\section{RESULTS}

The CS36 trial enrolled 403 patients, of which 369 completed the six-month treatment period. The baseline patient population characteristics have been presented elsewhere (21). A total of 21,836 item-level IPSS, 3119 QoL scores, and $1116 \mathrm{BII}_{\text {summary }}$ observations over the 6-month trial period were available for analysis in the current work. Figure 1 shows the mean time course for the total IPSS, the
QoL score, and the BII, respectively, in the CS36 trial. A marked drop in mean score was observed for all treatment arms on each BPH-LUTS scale and no dose-response relationship was apparent on any of the three scales. The Supplemental Material contains further details on the distribution of responses in each BPH-LUTS scale.

\section{Unidimensional Integrated Item Response Theory Modeling}

The item characteristic curves (ICCs) for the seven IPSS items, the QoL item, and the $\mathrm{BII}_{\text {summary }}$ item in the unidimensional integrated BPH-LUTS IRT model are shown in Fig. 2, and the corresponding ICC parameter estimates are shown in Table I. The latter were overall estimated with low uncertainty, although higher uncertainty was observed for $\mathrm{BII}_{\text {summary }}$ difficulty parameters. The discrimination parameter value was lowest for the Nocturia IPSS item (0.55) and

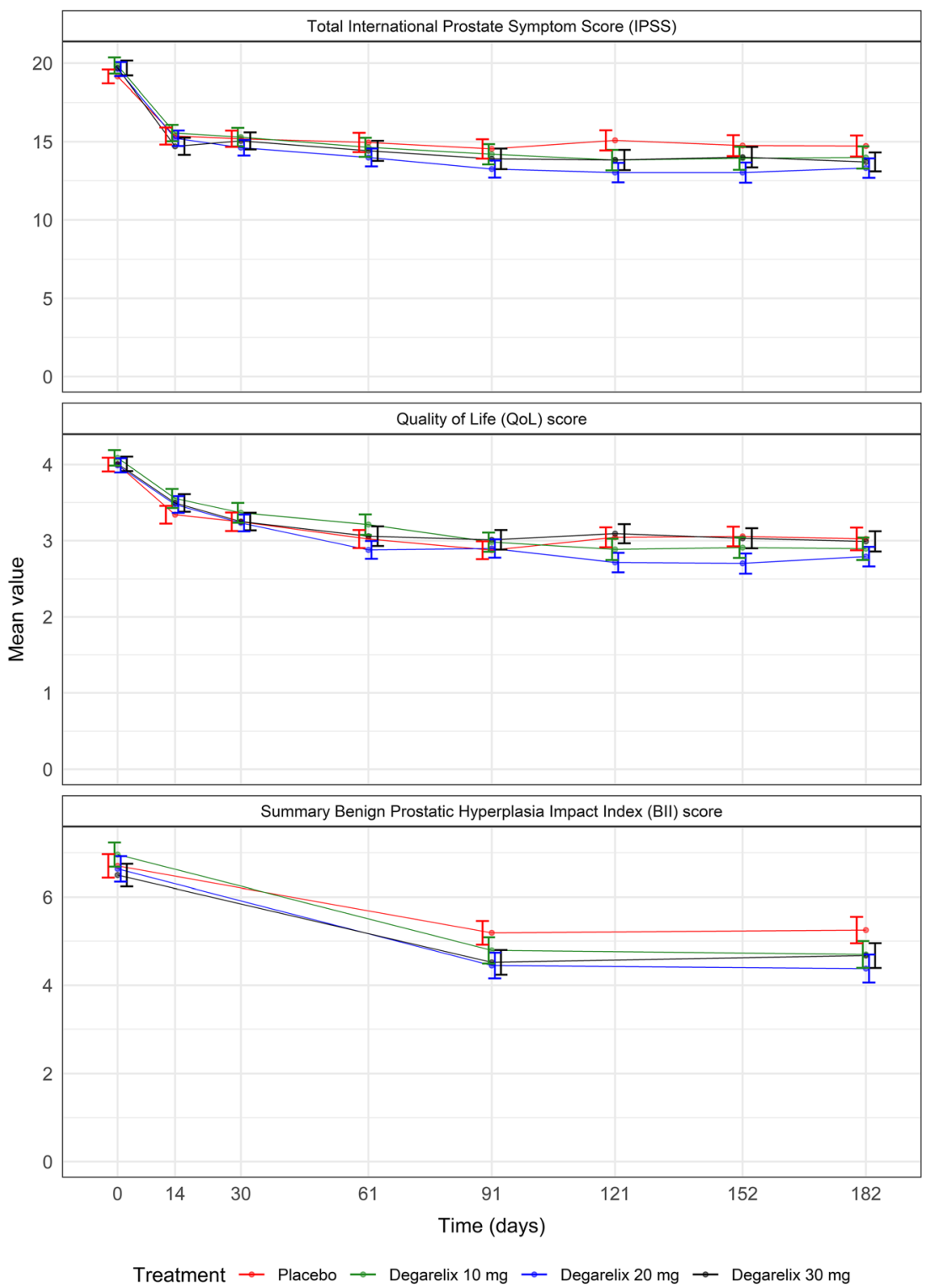

Fig. 1. Time course of the mean total International Prostate Symptom Score, Quality of Life score, and summary Benign Prostatic Hyperplasia Impact Index. Standard errors are indicated as error bars 
highest for the QoL item (1.22), indicating that they respectively have the lowest and highest sensitivity to change in disability. Adequate fit of the ICCs was observed with GAM diagnostics and these are shown in the Supplemental Material.

As shown in Fig. 3 and Table II, Fisher Information in the unidimensional integrated BPH-LUTS IRT model ranged from $3.7 \%$ for the IPSS Nocturia item to $17 \%$ for the QoL item. The pooled information content of all IPSS items represented $70.6 \%$ of the total information, the pooled information of IPSS voiding items represented $44.7 \%$ of the total information, and the pooled information of IPSS storage items represented $25.8 \%$ of the total information (Table II).

Figure 4a illustrates the relationship between patients' estimated latent disability in the unidimensional integrated IRT model and their observed total IPSS, observed QoL score, and observed $\mathrm{BII}_{\text {summary, }}$ respectively. High level of agreement was observed between latent disability and total IPSS, QoL, and BII summary $_{\text {(Pearson correlation coefficients }}$ of $0.96,0.77$, and 0.71 , respectively), indicating that the unidimensional IRT model's estimate of underlying BPHLUTS is in line with the observed score from each BPHLUTS measure. Comparison of the change from baseline in latent disability and the observed change from baseline in each scale is shown in Fig. 4b. Based on the vast majority of the illustrated data, a given patient with observed decreases of at least three, one, and one in total IPSS, QoL, and summary BII, respectively, is expected to have a decrease in latent BPH-LUTS disability. Further specification of the proportion of patients with decreased latent disability at each observed score change is presented in the Supplemental Material.

An exponential model with a drift component described the longitudinal placebo effect and an offset effect described the degarelix treatment effect, similar to the previous longitudinal IRT model considering only IPSS responses (21):

$$
\text { Placebo }=P \max \left(1-e^{-\frac{\ln (2)}{T \text { prog }} * \text { Time }}\right)+\text { Drift } * \text { Time }
$$

Disability $=$ Baseline + Placebo + Drug

Drug $=0$ if dose $=0$ and $\operatorname{Drug}=\theta$ if dose $>0$

$$
\text { and time }>0
$$

with Baseline being the baseline disability, Pmax the maximal placebo effect, Tprog the half-life to reach $P \max$, Drift the relapse/continued remission parameter, and Drug the offset drug effect of degarelix estimated as a fixed effect $(\theta)$. Between-subject variability (BSV) was implemented for Baseline, Pmax, and Drift assuming a normal distribution while BSV was implemented for Tprog assuming a lognormal distribution. In agreement with the previous finding in the IPSS IRT model (21), no dose-response or exposure-response relationship was observed and such models (slope and Emax) were not found to be significantly better than the effect of degarelix modeled as independent of dose or exposure. Estimation of the drug effect yielded a drop in objective function of 25.0 compared with the reduced model where the fixed effect parameter of degarelix treatment was fixed to zero. Covariate relationships were investigated for the

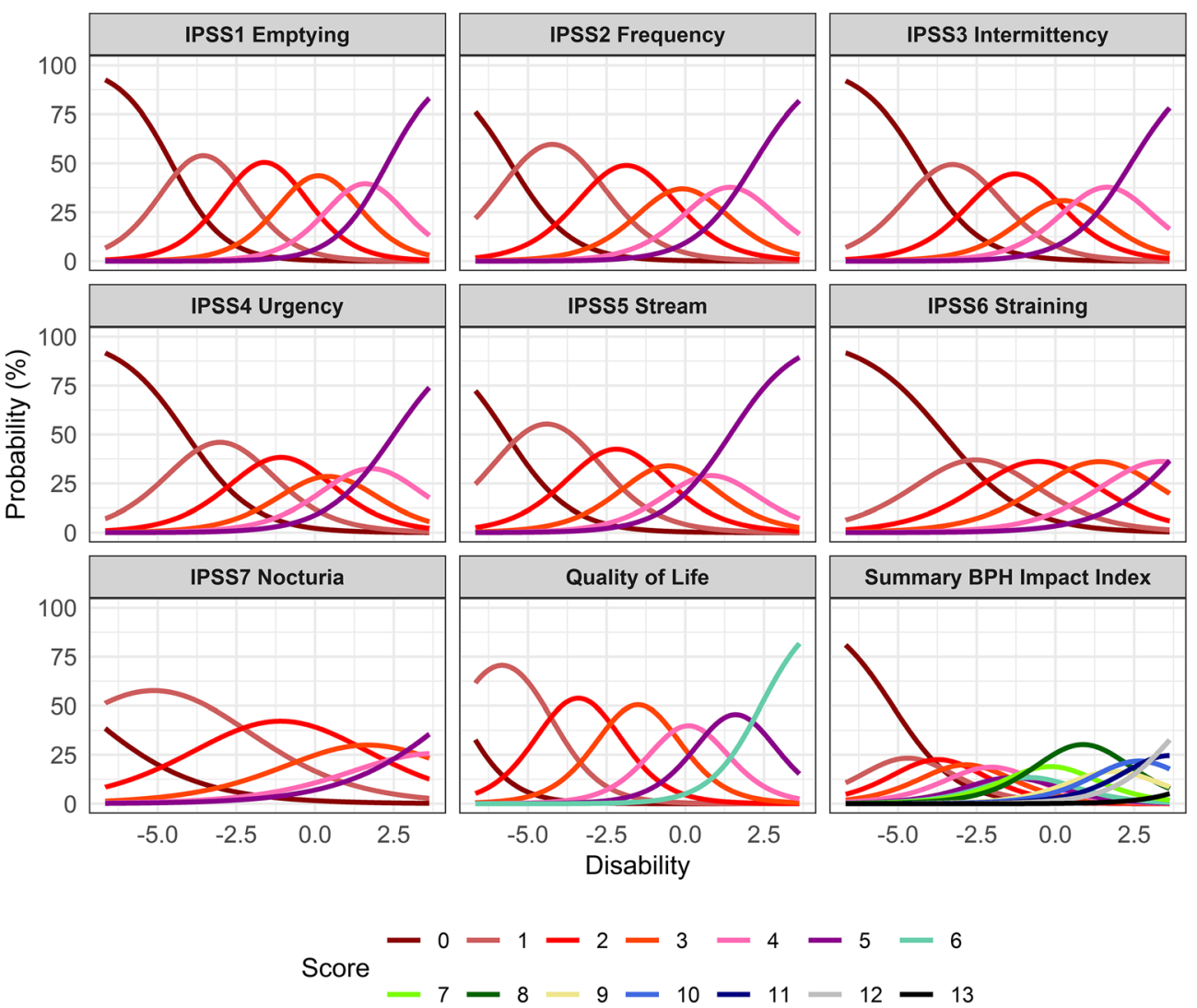

Fig. 2. Item characteristic curves in the unidimensional integrated item response theory model. IPSS, International Prostate Symptom Score; BPH, Benign Prostatic Hyperplasia 
Table I. Item Characteristic Curve Parameter Estimates in the Integrated Unidimensional Lower Urinary Tract Symptoms Due to Benign Prostatic Hyperplasia (BPH) Item Response Theory Model

\begin{tabular}{|c|c|c|}
\hline Parameter & Estimate & $\begin{array}{l}\text { Relative standard } \\
\text { error }(\%)\end{array}$ \\
\hline$a_{\text {IPSS1 }}$ & 1.19 & 7.3 \\
\hline $\mathrm{b}_{\text {IPSS } 1,1}$ & -4.56 & 6 \\
\hline $\mathrm{b}_{\mathrm{IPSS} 1,2}$ & 2.02 & 7.3 \\
\hline$b_{\text {IPSS } 1,3}$ & 1.86 & 6.8 \\
\hline $\mathrm{b}_{\mathrm{IPSS} 1,4}$ & 1.57 & 7 \\
\hline $\mathrm{b}_{\text {IPSS } 1,5}$ & 1.4 & 8.1 \\
\hline$a_{\text {IPSS2 }}$ & 1.04 & 6.8 \\
\hline $\mathrm{b}_{\text {IPSS } 2,1}$ & -5.55 & 6 \\
\hline $\mathrm{b}_{\text {IPSS } 2,2}$ & 2.65 & 7.3 \\
\hline $\mathrm{b}_{\text {IPSS } 2,3}$ & 2.06 & 6.7 \\
\hline $\mathrm{b}_{\text {IPSS } 2,4}$ & 1.49 & 7 \\
\hline $\mathrm{b}_{\text {IPSS } 2,5}$ & 1.53 & 7.5 \\
\hline $\mathrm{a}_{\text {IPSS3 } 3}$ & 1.04 & 7.5 \\
\hline $\mathrm{b}_{\text {IPSS } 3,1}$ & -4.31 & 6 \\
\hline$b_{\text {IPSS } 3,2}$ & 2.09 & 7.4 \\
\hline $\mathrm{b}_{\text {IPSS } 3,3}$ & 1.85 & 7.1 \\
\hline $\mathrm{b}_{\text {IPSS } 3,4}$ & 1.23 & 7.5 \\
\hline $\mathrm{b}_{\mathrm{IPSS} 3,5}$ & 1.53 & 8.2 \\
\hline$a_{\text {IPSS4 }}$ & 0.929 & 6.9 \\
\hline $\mathrm{b}_{\text {IPSS } 4,1}$ & -4.09 & 5.8 \\
\hline $\mathrm{b}_{\text {IPSS } 4,2}$ & 2.14 & 7 \\
\hline $\mathrm{b}_{\text {IPSS } 4,3}$ & 1.74 & 6.8 \\
\hline $\mathrm{b}_{\text {IPSS } 4,4}$ & 1.26 & 7.4 \\
\hline $\mathrm{b}_{\text {IPSS } 4,5}$ & 1.45 & 7.9 \\
\hline $\mathrm{a}_{\text {IPSS5 }}$ & 0.972 & 7 \\
\hline $\mathrm{b}_{\text {IPSS5, } 1}$ & -5.68 & 6.2 \\
\hline$b_{\text {IPSS } 5,2}$ & 2.56 & 7.7 \\
\hline $\mathrm{b}_{\text {IPSS } 5,3}$ & 1.87 & 7 \\
\hline $\mathrm{b}_{\text {IPSS5 }, 4}$ & 1.45 & 7.1 \\
\hline $\mathrm{b}_{\text {IPSS } 5,5}$ & 1.23 & 7.7 \\
\hline$a_{\text {IPSS6 }}$ & 0.774 & 8.1 \\
\hline$b_{\text {IPSS6, } 1}$ & -3.55 & 6.3 \\
\hline$b_{\text {IPSS } 6,2}$ & 2.01 & 8 \\
\hline$b_{\text {IPSS } 6,3}$ & 1.96 & 7.9 \\
\hline$b_{\text {IPSS } 6,4}$ & 1.96 & 8.6 \\
\hline $\mathrm{b}_{\text {IPSS } 6,5}$ & 1.96 & 10.3 \\
\hline$a_{\text {IPSS7 }}$ & 0.549 & 7.6 \\
\hline $\mathrm{b}_{\text {IPSS7, } 1}$ & -7.52 & 6.8 \\
\hline $\mathrm{b}_{\text {IPSS } 7,2}$ & 4.79 & 7.9 \\
\hline$b_{\text {IPSS7,3 }}$ & 3.28 & 7.4 \\
\hline $\mathrm{b}_{\text {IPSS7 }, 4}$ & 2.26 & 8.1 \\
\hline $\mathrm{b}_{\text {IPSS7,5}}$ & 1.91 & 9.9 \\
\hline $\mathrm{a}_{\mathrm{QoL}}$ & 1.22 & 6.4 \\
\hline $\mathrm{b}_{\mathrm{QoL} 1}$ & -7.26 & 6.3 \\
\hline $\mathrm{b}_{\mathrm{QoL}, 2}$ & 2.88 & 9.4 \\
\hline $\mathrm{b}_{\mathrm{QoL}, 3}$ & 1.97 & 6.8 \\
\hline $\mathrm{b}_{\mathrm{QoL}, 4}$ & 1.82 & 6.4 \\
\hline $\mathrm{b}_{\mathrm{QoL}, 5}$ & 1.38 & 6.7 \\
\hline $\mathrm{b}_{\mathrm{QoL}, 6}$ & 1.61 & 7.5 \\
\hline$a_{B I I}$ & 0.975 & 7.9 \\
\hline $\mathrm{b}_{\mathrm{BII}, 1}$ & -5.18 & 6.6 \\
\hline $\mathrm{b}_{\mathrm{BII}, 2}$ & 0.974 & 13.8 \\
\hline $\mathrm{b}_{\mathrm{BII}, 3}$ & 0.943 & 11.8 \\
\hline $\mathrm{b}_{\mathrm{BII}, 4}$ & 0.828 & 11.1 \\
\hline $\mathrm{b}_{\mathrm{BII}, 5}$ & 0.775 & 10.4 \\
\hline $\mathrm{b}_{\mathrm{BII}, 6}$ & 0.549 & 11.4 \\
\hline$b_{\mathrm{BII}, 7}$ & 0.552 & 11.1 \\
\hline $\mathrm{b}_{\mathrm{BUL} 8}$ & 0.789 & 10 \\
\hline
\end{tabular}

Table I. (continued)

\begin{tabular}{lcc}
\hline Parameter & Estimate & $\begin{array}{c}\text { Relative standard } \\
\text { error }(\%)\end{array}$ \\
$\mathrm{b}_{\mathrm{BII}, 9}$ & 1.28 & 9.7 \\
$\mathrm{~b}_{\mathrm{BII}, 10}$ & 0.685 & 14.5 \\
$\mathrm{~b}_{\mathrm{BII}, 11}$ & 0.91 & 15.5 \\
$\mathrm{~b}_{\mathrm{BII}, 12}$ & 1.03 & 20.1 \\
$\mathrm{~b}_{\mathrm{BII}, 13}$ & 2.48 & 28.8 \\
Post-baseline disability variance & 2.59 & 6.3 \\
Post-baseline disability mean & -1.53 & 5.9
\end{tabular}

Relative standard error was calculated as $100 *$ (standard error of estimate / estimate). The typical value of $\eta$-shrinkage was $8.2 \%$ $a$, discrimination parameters; $b$, difficulty parameters for each score using the delta method (e.g., $\mathrm{B}_{\text {IPSS } 1,2}=\mathrm{b}_{\text {IPSS } 1,1}+\mathrm{b}_{\text {IPSS } 1,2}$ ); IPSS, International Prostate Symptom Score; QoL, Quality of Life; BII, Summary BPH Impact Index; IPSS1, incomplete emptying; IPSS2, frequency; IPSS3, intermittency; IPSS4, urgency; IPSS5, weak stream; IPSS6, straining; IPSS7, nocturia

Baseline, Pmax, and Drug parameters. Following backwards elimination, post-void residual volume on Baseline disability was found to be the only significant covariate $(p<0.001)$. The final longitudinal model parameter estimates in the unidimensional BPH-LUTS IRT model are presented in Table III along with their relative standard errors. Categorical VPCs for each item in the unidimensional integrated IRT model are shown in the Supplemental Material, showing adequate model fit for all nine items in all four CS36 treatment arms.

\section{Multidimensional Item Response Theory Modeling}

Results of factor analyses with one and two dimensions, respectively, are shown in Table IV. In the bi-dimensional factor analysis, the IPSS storage items and the QoL score were mainly reflected by one dimension while IPSS voiding items were mainly reflected by the other dimension. Moreover, the $\mathrm{BII}_{\text {summary }}$ item was found to be reflected by both factors to an almost equal extent. Hence, a bidimensional integrated IRT model was developed, where responses to IPSS voiding items were driven by a "voiding" disability, responses to IPSS storage items and the QoL score were driven by a "storage" disability, and a compensatory graded response model allowed for responses of $\mathrm{BII}_{\text {summary }}$ to be driven by both voiding and storage disability. The ICC parameter estimates in the bi-dimensional integrated IRT model are shown in Table I. Factor analysis using three dimensions showed similar factor loadings to the twodimensional factor analysis, except for the Nocturia item being mainly reflected by the third dimension. As at least three items are needed per latent variable to preserve identification, a three-dimensional IRT model was not pursued.

Similar to the IPSS IRT model (21), a Weibull model was used to describe the longitudinal placebo effect of the underlying disability on each scale:

Placebo $=P \max \left(1-e^{-\left(\frac{\ln (2)}{T_{\text {prog }} * \text { Time }}\right)^{\mathrm{WEI}}}\right)+$ Drift $*$ Time 
where WEI is the Weibull exponent. The drug effect model consisted of separate offset effects on each latent variable scale:

Disability $_{\text {Voiding }}=$ Baseline $_{V_{\text {oiding }}}+$ Placebovoiding $_{\text {Pasug }}+$ Druiding. $_{\text {. }}$ Disability $_{\text {Storage }}=$ Baseline $_{\text {Storage }}+$ Placebo $_{\text {Storage }}+$ Drug $_{\text {Storage }}$

The longitudinal bidimensional integrated model minimized successfully and its parameter estimates are presented in Table V. Due to model instability, it was not possible to obtain parameter uncertainty through the covariance step or perform covariate analysis. With the bidimensional model, a drop in AIC of 2862.2 was observed compared with the unidimensional integrated BPH-LUTS model. Categorical VPCs for each item in the bidimensional integrated IRT model with a compensatory graded response model for the $\mathrm{BII}_{\text {summary }}$ item are presented in the Supplemental Material.

\section{Power Determination}

Figure 5 shows the power of the integrated and IPSS IRT models, respectively. Compared with the unidimensional IRT model considering only IPSS data, the integrated unidimensional IRT model displayed a sample size reduction of $16 \%$ to detect a drug effect at $80 \%$ power $\left(N_{\text {IRT-IPSS-Unidimensional }}=\right.$
132 vs. $N_{\text {IRT-Integrated-Unidimensional }}=111$, well below the actual trial size of 403 patients). At each sample size, the type I error rate was found to be similar in both models (Supplemental Material), and hence, no type-I error adjustment to the power estimates was performed.

\section{DISCUSSION}

The current paper presents models integrating multiple BPH-LUTS scales using IRT. To our knowledge, this is the first model integrating several endpoints within the therapeutic area. We investigated the information content within different BPH-LUTS measures and compared the power to detect a treatment effect of the integrated IRT approach with a previously developed IRT models that considered only IPSS responses. Assessing the effect of drugs on the voiding and storage IPSS subscores is common practice in BPH-LUTS clinical trials although its clinical meaningfulness is not established $(13,23,35-37)$. A previous longitudinal bidimensional IRT model, based on item-level IPSS, aimed to reflect this type of analysis while preserving item-level information (21); in the current work, this model was further extended by including data from the QoL and BII scales. This allowed further characterization of underlying disability and
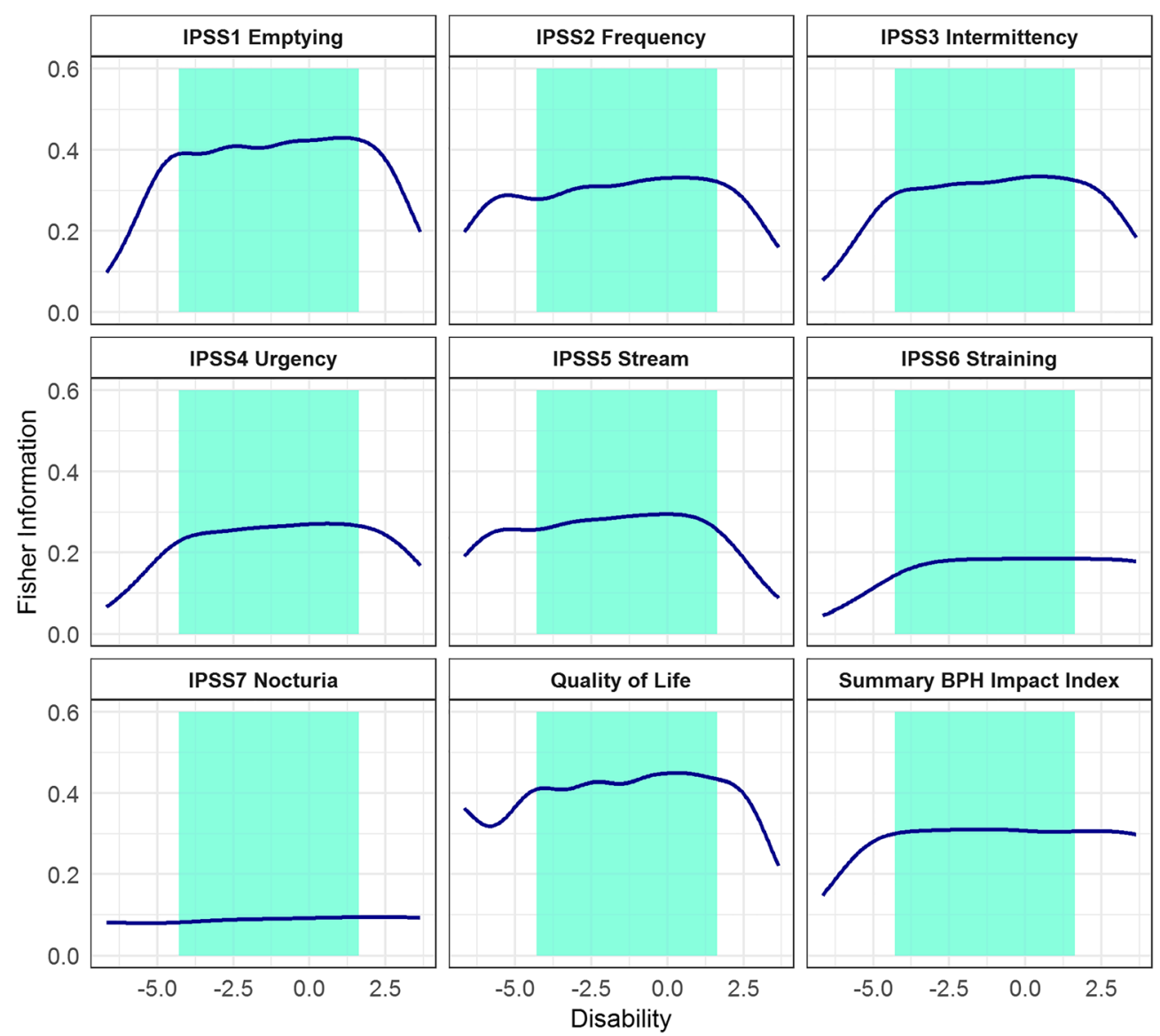

Fig. 3. Fisher Information Content of each International Prostate Symptom Score item, the Quality of life score, and the summary Benign Prostatic Hyperplasia (BPH) Impact Index across the estimated disability in the unidimensional integrated item response theory model. Shaded areas indicate the disability range for $95 \%$ of the study population 
Table II. Fisher Information Content Ranking in the Unidimensional Integrated Item Response Theory Model

\begin{tabular}{llcc}
\hline Item & Item subscore category & \% of total Fisher information & Cumulative \% total \\
\hline Quality of Life score & - & 17 & 17 \\
IPSS1 & Voiding & 15.4 & 32.4 \\
IPSS2 & Storage & 12.4 & 44.8 \\
BII summary & - & 12.4 & 57.2 \\
IPSS3 & Voiding & 11.9 & 69.1 \\
IPSS5 & Voiding & 10.7 & 79.8 \\
IPSS4 & Storage & 9.7 & 89.5 \\
IPSS6 & Voiding & 6.8 & 96.3 \\
IPSS7 & Storage & 3.7 & 100 \\
\hline
\end{tabular}

IPSS, International Prostate Symptom Score; BII $_{\text {summary }}$, Benign Prostatic Hyperplasia Impact Index sum of scores; IPSS1, incomplete emptying; IPSS2, frequency; IPSS3, intermittency; IPSS4, urgency; IPSS5, weak stream; IPSS6, straining; IPSS7, nocturia

differentiation of the effect of treatment on the "generalized" voiding and storage latent variables, respectively.
In the unidimensional integrated BPH-LUTS IRT model, all scales were modeled assuming a common

a

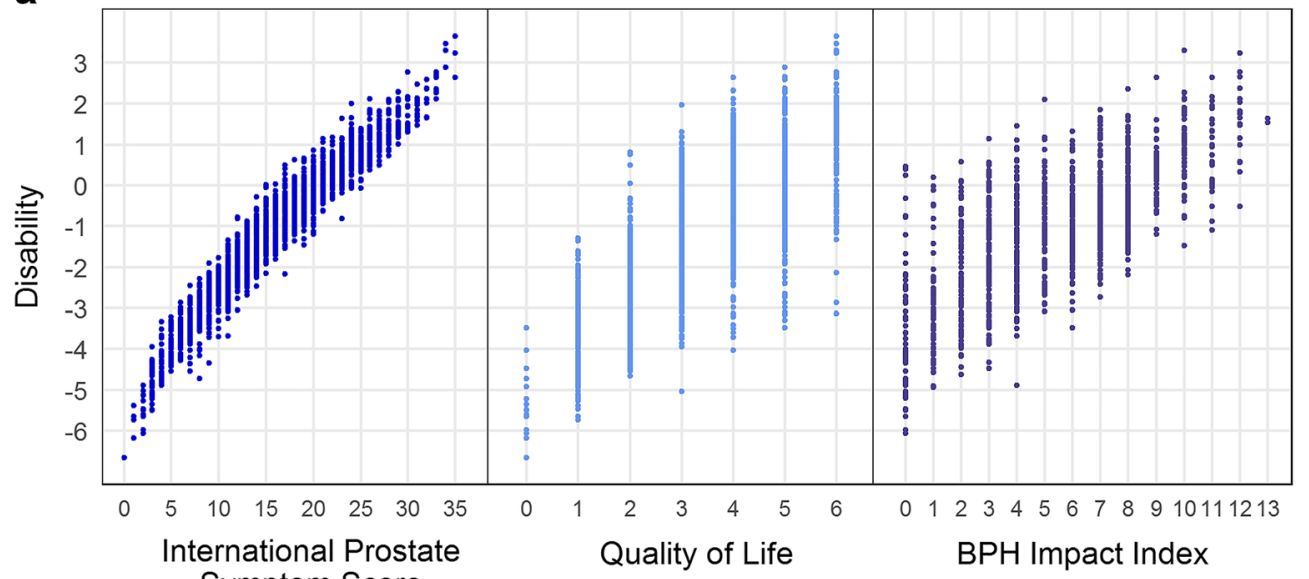

Symptom Score

b

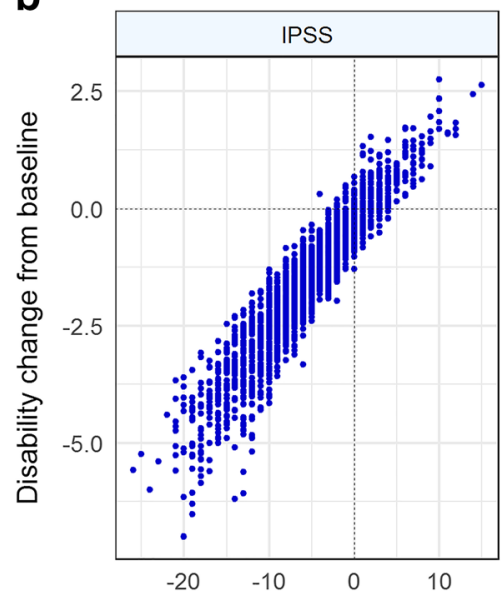

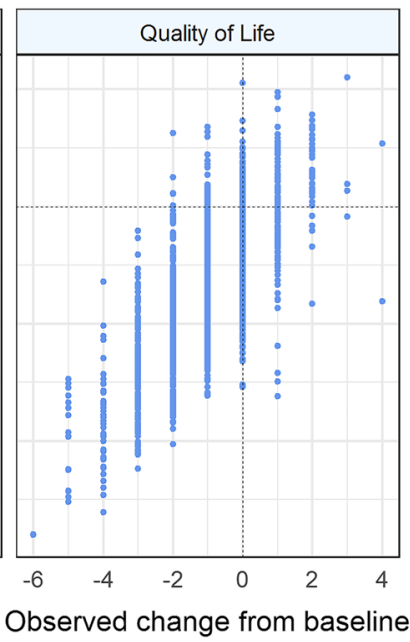

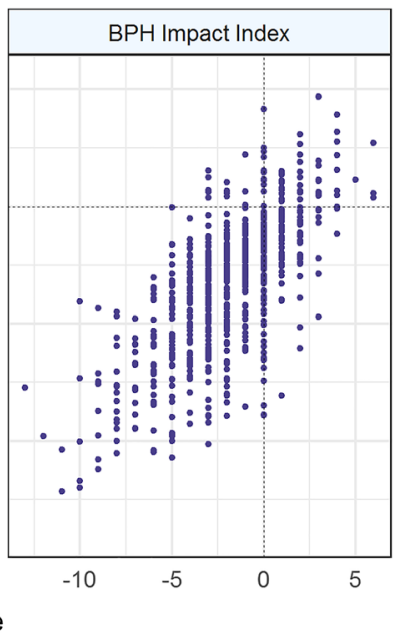

Fig. 4. a Disability estimated from the unidimensional integrated item response theory model vs. the observed total International Prostate Symptom Score (IPSS), the observed Quality of Life (QoL) score, and the observed summary Benign Prostatic Hyperplasia (BPH) Impact Index, respectively, b Change from baseline in disability estimates from the unidimensional integrated item response theory model $v s$. observed change from baseline in total IPSS, observed QoL score, and observed summary BPH Impact Index, respectively, in 403 patients over the 6-month trial period 
underlying disability. Unidimensional IRT modeling allows for determination of which item best describes latent disability amongst all items in all BPH-LUTS scales. This overall perspective is lost in a multidimensional IRT setting, since here inference regarding information content can only be made within each scale separately. This may explain why other pharmacometric IRT studies have applied a unidimensional modeling approach to analyze responses from multiple scales (18-20). In the current unidimensional model, the QoL item was found to be the overall most informative, contributing to $17 \%$ of the total information content, highlighting the importance of this question for assessing BPH-LUTS. The IPSS incomplete emptying item was the second-most informative item, yielding $15.4 \%$ of the total Fisher information. This is in line with the previously presented unidimensional IPSS IRT model, where the incomplete emptying item was found to be the most informative (21). Approximately $70 \%$ of the total information content was accounted for by the IPSS items, confirming the importance of this scale in characterizing BPH-LUTS and supporting its common use as a primary outcome measure in BPH-LUTS clinical trials. The higher combined information content contribution of IPSS voiding items compared with IPSS storage items is also in line with results from the previous IPSS IRT analysis (21).

The minimal detectable difference (MDD) in observed total IPSS has previously been reported as being at least three points (17) and the current work supports this as decreases in latent disability were strictly observed using this threshold (in accordance with $99.9 \%$ of the data). However, as discussed in previous work (21), decreases in latent disability may also be obtained above the MDD, advocating the use of an IRT approach rather than regarding only the summary IPSS to assess patient's underlying BPH-LUTS. For the QoL score, a decrease of at least one point corresponds to predominantly decreases in IRT-derived latent disability (in $96.8 \%$ of patients as shown in the Supplemental Material). This is in line with previous research, where mean QoL reductions ranging 0.5 to 0.8 corresponded to perceived disease improvement in different groups of patients (38). Furthermore, other authors have used a decrease in QoL score of one as this represents a qualitative change on an ordinal scale (39). The current findings may thus have implications for clinical research and the assessment of drug efficacy within BPHLUTS based on the QoL score. A decrease of at least 0.5 BII points (i.e., 1 point on the observed level) has been reported as the MDD for this scale (17). The current results are in line with this, as this to a large extent corresponds to decreases in latent disability (in $93.6 \%$ of patients as shown in the Supplemental Material).

The effect of post-void residual volume (PVR) on baseline latent disability was the only covariate relationship retained in the longitudinal unidimensional integrated IRT model following the stepwise procedure. Weak correlation between symptom severity as expressed by the IPSS and physiologic measures, here amongst PVR, has been reported (40). However, the current finding suggests that post-void residual volume is indicative of underlying BPH-LUTS severity as assessed by several disease-specific scales, and further research should aim to confirm this finding.

Factor analysis with two dimensions indicated that IPSS storage items and the QoL score were predominantly correlated with the same dimension. This is supported by the correlation between IPSS storage items and the QoL score previously highlighted by other authors (15,41-43). High correlation between the $\mathrm{BII}_{\text {summary }}$ item and both the storage as well as voiding disability was observed, and a compensatory model was used to describe this finding. Each individual BII item may be separately correlated with either the storage or voiding disability, ultimately leading to the $\mathrm{BII}_{\text {summary }}$ reflecting this. Very limited research has to date been performed examining the level of correlation between individual IPSS and BII items (44), and these indicate that a combination of IPSS voiding and storage items may correlate

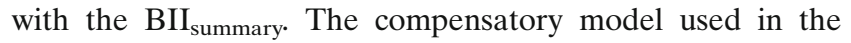
current work allows for a high value on either the voiding or storage disability scale to potentially compensate for a low value on the other scale, ultimately resulting in a high probability of a $\mathrm{BII}_{\text {summary }}$ score. It may be of interest to investigate other within-item multidimensional models, such as the non-compensatory/partially compensatory model (45),

Table III. Longitudinal Parameter Estimates for the Unidimensional Item Response Theory (IRT) Model

\begin{tabular}{lcc}
\hline Parameter & Longitudinal unidimensional integrated IRT model \\
\cline { 2 - 3 } & Value & Relative standard error \\
\hline Baseline & -0.0993 & 57.1 \\
Pmax (maximal placebo response) & -1.22 & 9.2 \\
Tprog (placebo half-life) & 16.2 & 17.5 \\
Drug effect & -0.565 & 19.3 \\
Covariates & & 24.9 \\
Post-void residual volume on baseline & 0.00327 & 5.5 \\
Interindividual variability (IIV) & $104.4 \%$ & 13.9 \\
IIV Baseline & $134.9 \%$ & 9 \\
IIV Pmax & $0.9 \%$ & 12.6 \\
IIV Drift & $51.7 \%$ & 46.3 \\
IIV Tprog & $15.5 \%$ & 36.5 \\
IIV Baseline-Pmax correlation & $45.4 \%$ & \\
IIV Pmax-Drift correlation & & \\
\hline
\end{tabular}


Table IV. Factor Loadings Obtained from Confirmatory Factor Analysis (CFA) of the Nine Items Using One and Two Dimensions, Respectively

\begin{tabular}{llll}
\hline Item & Factor loadings using 1 factor & \multicolumn{2}{l}{ Factor loadings using 2 factors } \\
\cline { 2 - 4 } & & Factor 1 & Factor 2 \\
\hline IPSS1 & & -0.605 & 0.462 \\
IPSS2 & 0.756 & -0.228 & 0.763 \\
IPSS3 & 0.702 & -0.672 & 0.349 \\
IPSS4 & 0.709 & -0.310 & 0.613 \\
IPSS5 & 0.662 & -0.612 & 0.367 \\
IPSS6 & 0.683 & -0.806 & 0.113 \\
IPSS7 & 0.600 & -0.108 & 0.537 \\
Quality of Life (QoL) & 0.459 & -0.313 & 0.752 \\
Summary BPH Impact Index (BII & 0.755 & -0.516 & 0.462 \\
\hline
\end{tabular}

In the CFA with two factors, numbers in italic emphasize the largest factor loading value (covariance between each item and factor). Higher factor loadings indicate closer association with the factor

IPSS1, incomplete emptying; IPSS2, frequency; IPSS3, intermittency; IPSS4, urgency; IPSS5, weak stream; IPSS6, straining; IPSS7, nocturia

where high disability on both scales is needed to obtain a high score probability. Due to its complexity and requirement of a larger number of parameters (separate difficulty parameters on each scale), this type of within-item multidimensionality was not investigated in the current work. Compared with a longitudinal bi-dimensional integrated IRT model solely attributing the $\mathrm{BII}_{\text {summary }}$ item to the voiding latent variable, the compensatory model yielded a drop in AIC of 54.9 points (data not shown).

Incorporating longitudinal QoL and BII scores along with longitudinal item-level IPSS responses in the pharmacometric IRT framework reduced the sample size by $16 \%$ to detect a drug effect at $80 \%$ compared with considering only item-level IPSS responses. This finding showcases the benefit of utilizing all available information from disease-specific scales within BPH-LUTS to assess treatment effect in a clinical trial setting, made possible by the IRT approach. Quantification of the increase in power to detect a drug effect when simultaneously modeling all scale endpoints as opposed to only considering the primary endpoint marker has to our knowledge not been presented within other therapeutic areas. It may therefore be of interest to further investigate the power of the integrated IRT approach in therapeutic areas where clinical trials commonly include multiple disease-specific scales to assess the treatment effect. The currently reported relative increase in power to detect a drug effect with the integrated unidimensional IRT model is expected to be similar within the context of bidimensional IRT modeling, considering that the difference in modeled data is the same (IPSS, QoL, and BII vs. only IPSS). Although the longitudinal bidimensional integrated IRT model yielded a much better fit in terms of likelihood, its complexity and resulting instability may ultimately favor use of the unidimensional approach, which also described the data adequately. For these reasons, comparison of power between the integrated and IPSS bidimensional model, respectively, was not investigated in the current work. Lastly, the observed total IPSS is the common primary endpoint marker in BPH-LUTS clinical trials while pharmacometric IRT focuses on latent disability as the estimand summary measure (46). Pharmacometric IRT possesses higher power to detect a drug effect compared with the total IPSS approach (21), and hence the latter may not be meaningfully applied when the sample size is determined based on IRT-derived latent disability (using only item-level IPSS or multiple BPHLUTS scales, respectively).

A limitation of the current study is that item-level BII scores were not available for analysis. The information content of each individual BII item is likely to vary, whereas only considering the summary score, as in the current study, assumes it is the same. Accounting for this variation in information content across BII items within the IRT framework may further increase the characterization of $\mathrm{BPH}$ LUTS as well as the power to detect a drug effect of the integrated IRT model. Incorporating summary-level score

Table V. Parameter Estimates of the Longitudinal Bidimensional Integrated Item Response Theory Model

\begin{tabular}{|c|c|}
\hline Parameter & Value \\
\hline Baseline $_{\mathrm{V}}$ (voiding scale) & -0.0321 \\
\hline Baseline $_{\mathrm{S}}$ (storage scale) & -0.0347 \\
\hline$P \max _{\mathrm{V}}$ (maximal placebo response voiding scale) & -0.939 \\
\hline$P \max _{\mathrm{S}}$ (maximal placebo response storage scale) & -1.36 \\
\hline$T \operatorname{prog}_{\mathrm{V}}$ (placebo half-life voiding scale) & 12.3 \\
\hline$T$ prog $_{\text {s }}$ (placebo half-life storage scale) & 14 \\
\hline Weibull shape parameter (common for both scales) & 1.6 \\
\hline Drug effect voiding scale & -0.369 \\
\hline Drug effect storage scale & -0.634 \\
\hline \multicolumn{2}{|l|}{ Interindividual variability (IIV) } \\
\hline IIV Baseline $_{\mathrm{v}}$ (voiding scale) & $98.6 \%$ \\
\hline IIV Baseline $_{\text {S }}$ (storage scale) & $128.1 \%$ \\
\hline 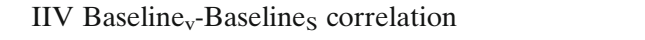 & $28.9 \%$ \\
\hline IIV Pmax (common for both scales) & $114.9 \%$ \\
\hline IIV Tprog (common for both scales) & $60.8 \%$ \\
\hline IIV Drift (common for both scales) & $0.6 \%$ \\
\hline IIV Pmax-Drift correlation & $33.2 \%$ \\
\hline
\end{tabular}

Interindividual variability was assumed normally distributed for the Baseline, Pmax, and Drift parameters and lognormally distributed for the Tprog parameter. No relative standard errors were computed due to model stability issues 


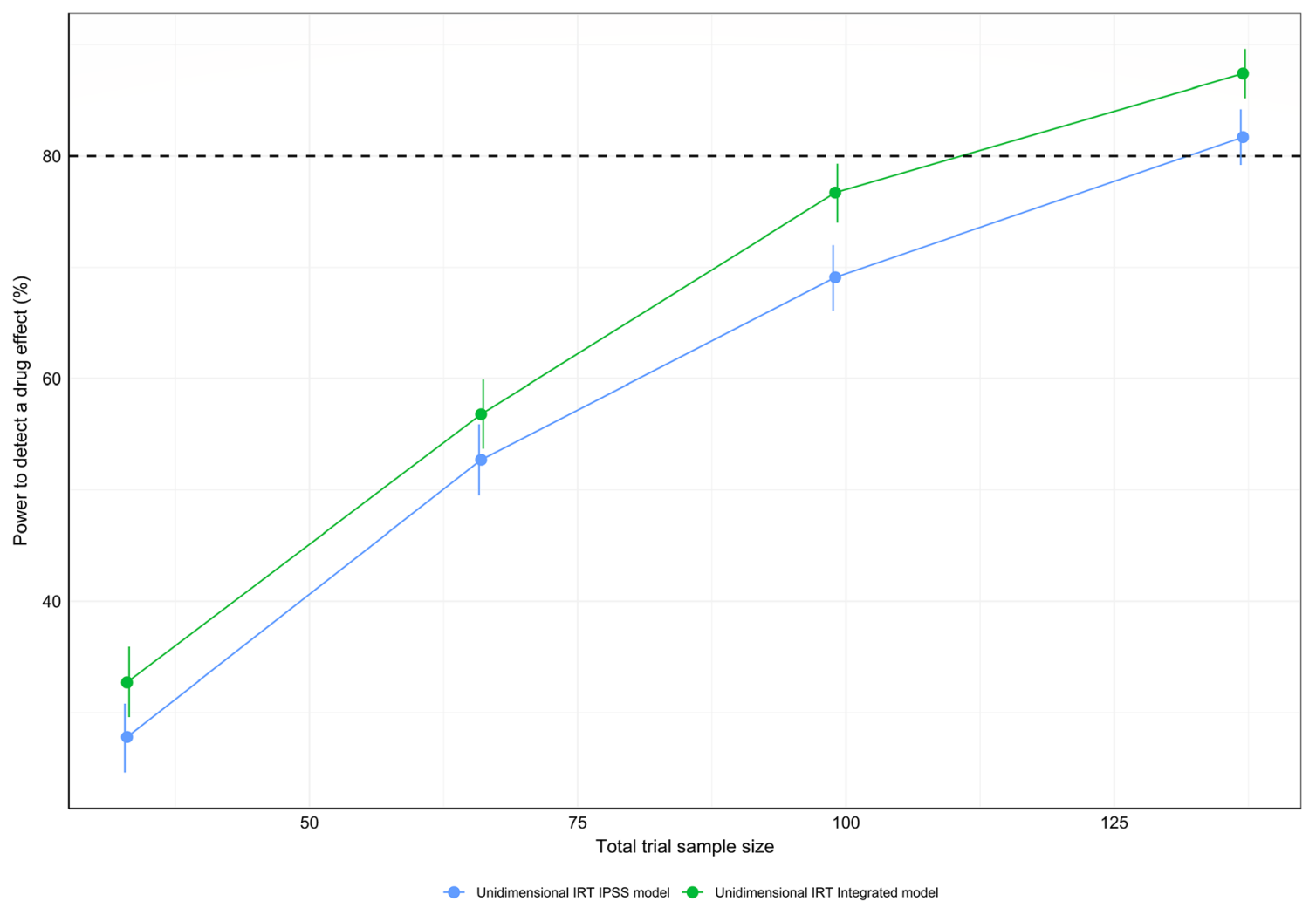

Fig. 5. Power curves for the unidimensional integrated and the unidimensional International Prostate Symptom Score (IPSS) item response theory pharmacometric models, respectively, using a stochastic simulation and estimation procedure. One thousand simulated data sets from the integrated unidimensional item response theory model at sample sizes of 33, 66, 99, and 137 patients were used for model estimation with the respective full (with a drug effect parameter) and reduced (without a drug effect parameter) models. Vertical lines indicate the $95 \%$ confidence interval for the calculated power estimates. A decrease of 3.84 was used to establish significant improvement in objective function between the full and reduced models of the respective approaches

data as an item, when item-level data are not available, has been reported previously in integrated IRT modeling (19). Although inferior compared with analyzing item-level BII scores, ignoring the $\mathrm{BII}_{\text {summary }}$ data will lead to a loss of information, as shown by its Fisher Information content contribution in the unidimensional integrated IRT model (Table II). Further, the BII $_{\text {summary }}$ was assessed at three visits (baseline, 3 months post-dose, and 6 months post-dose) while item-level IPSS and the QoL score were measured at eight visits. The lower number of $\mathrm{BII}_{\text {summary }}$ observations may explain the overall higher uncertainty of $\mathrm{BII}_{\text {summary }}$ difficulty parameters compared with those estimated for individual IPSS items and the QoL score. Moreover, similar to the longitudinal bidimensional IRT model based on item-level IPSS (21) as well as other multidimensional pharmacometric IRT models $(24,25)$, the complexity of the longitudinal bidimensional integrated IRT model led to instability issues. It was hence not possible to obtain the uncertainty of longitudinal parameters or perform covariate analysis for this model. For the same reason, simultaneous estimation of ICCs and longitudinal parameters was not possible. More advanced and time-consuming techniques such as the bootstrap may be used to obtain parameter precision but was not performed here. The longitudinal bidimensional integrated IRT model minimized succesfully and showed adequate item and summary-level data description as assessed through VPCs; the longitudinal parameters were therefore ultimately deemed trustworthy. Lastly, in the longitudinal unidimensional integrated IRT model, simultaneously estimating the ICCs and longitudinal parameters decreased the objective function value by 16.7 points (data not shown) compared with fixing the ICCs. This was not significant given 63 degrees of freedom (63 ICC parameters) under a $\chi^{2}$ distribution.

Although validated to assess BPH-LUTS $(16,17,47)$, neither the IPSS, the QoL score, or the BII assesses incontinence, which may be an important and bothersome symptom in patients with BPH-LUTS $(14,48)$. Extending the current models to include such information using, e.g., the Incontinence Severity Index (49), the Epidemiology of LUTS questionnaire (50), and/or the International Consultation on Incontinence Modular Questionnaire (51) may further enhance the characterization of BPH-LUTS and its progression as well as further increase the power to detect a drug effect compared with only regarding the IPSS. In this context, it may also be of benefit to investigate the inclusion of generic PROs such as, e.g., the EuroQol-5 Domain scale (52) (EQ5D) and the Visual Analogue Scale $(53,54)$, potentially while guiding responses from these scales towards BPH-LUTS using a supervised IRT approach $(55,56)$.

\section{CONCLUSION}

IRT modeling was used to integrate data from multiple disease-specific PRO endpoints within BPH-LUTS into a 
single model. A sample size reduction of $16 \%$ to detect a drug effect at $80 \%$ power was obtained with the unidimensional integrated IRT model compared with its counterpart IPSS IRT model. This study shows that utilizing the information content across IPSS, QoL, and BII scales in an integrated IRT framework results in a modest but meaningful increase in power to detect a drug effect.

\section{ACKNOWLEDGMENTS}

This work was funded jointly by the Danish Innovation Fund (grant number 5189-00064b), Ferring Pharmaceuticals A/S, and the Swedish Research Council Grant 2018-03317.

\section{AUTHOR CONTRIBUTIONS}

Y.K.L wrote the manuscript; Y.K.L. analyzed the data; Y.K.L., T.M.L, A.C.H., M.O.K., and D.M.J designed the research; T.M.L, A.C.H., M.O.K., and D.M.J reviewed the manuscript.

\section{FUNDING INFORMATION}

Open access funding provided by Uppsala University.

\section{COMPLIANCE WITH ETHICAL STANDARDS}

Conflict of Interest Y.K.L and D.M.J. are employees of Ferring Pharmaceuticals A/S. The authors report no other conflicts of interest.

Open Access This article is licensed under a Creative Commons Attribution 4.0 International License, which permits use, sharing, adaptation, distribution and reproduction in any medium or format, as long as you give appropriate credit to the original author(s) and the source, provide a link to the Creative Commons licence, and indicate if changes were made. The images or other third party material in this article are included in the article's Creative Commons licence, unless indicated otherwise in a credit line to the material. If material is not included in the article's Creative Commons licence and your intended use is not permitted by statutory regulation or exceeds the permitted use, you will need to obtain permission directly from the copyright holder. To view a copy of this licence, visit http://creativecommons.org/licenses/by/4.0/.

\section{REFERENCES}

1. Abrams P, Cardozo L, Fall M, Griffiths D, Rosier P, Ulmsten U, et al. The standardisation of terminology in lower urinary tract function: report from the Standardisation Sub-Committee of the International Continence Society. Urology. 2003;61(1):37-49.

2. Berry SJ, Coffey DS, Walsh PC, Ewing LL. The development of human benign prostatic hyperplasia with age. J Urol. 1984;132(3):474-9.

3. Medina JJ, Parra RO, Moore RG. Benign prostatic hyperplasia (the aging prostate). Med Clin North Am. 1999;83(5):1213-29.

4. Caine M. The present role of alpha-adrenergic blockers in the treatment of benign prostatic hypertrophy. J Urol. 1986;136(1):1-4.
5. McNaughton-Collins M, Barry MJ. Managing patients with lower urinary tract symptoms suggestive of benign prostatic hyperplasia. Am J Med. 2005;118(12):1331-9.

6. Chute CG, Panser LA, Girman CJ, Oesterling JE, Guess HA, Jacobsen SJ, et al. The prevalence of prostatism: a populationbased survey of urinary symptoms. J Urol. 1993;150(1):85-9.

7. Homma Y, Kawabe K, Tsukamoto T, Yamanaka H, Okada K, Okajima E, et al. Epidemiologic survey of lower urinary tract symptoms in Asia and Australia using the international prostate symptom score. Int J Urol. 1997;4(1):40-6.

8. Hunter Duncan JW, Berra-Unamuno A, Martin-Gordo A. Prevalence of urinary symptoms and other urological conditions in Spanish men 50 years old or older. J Urol. 1996;155(6):1965-70.

9. Haidinger G, Madersbacher S, Waldhoer T, Lunglmayr G, Vutuc C. The prevalence of lower urinary tract symptoms in Austrian males and associations with sociodemographic variables. Eur J Epidemiol. 1999;15(8):717-22.

10. Sagnier PP, MacFarlane G, Richard F, Botto H, Teillac P, Boyle P. Results of an epidemiological survey using a modified American Urological Association symptom index for benign prostatic hyperplasia in France. J Urol. 1994;151(5):1266-70.

11. Tan HY, Choo WC, Archibald C, Esuvaranathan K. A community based study of prostatic symptoms in Singapore. J Urol. 1997;157(3):890-3.

12. Barry MJ, Fowler FJ, O'Leary MP, Bruskewitz RC, Holtgrewe HL, Mebust WK, et al. The American Urological Association symptom index for benign prostatic hyperplasia. The Measurement Committee of the American Urological Association. J Urol. 1992;148(5):1549-57 discussion 1564.

13. US Food and Drug Administration. Guidance for the nonclinical and clinical investigation of devices used for the treatment of benign prostatic hyperplasia (BPH). (2010). $<$ https://www.fda.gov/regulatory-information/search-fda-guidance-documents/guidance-non-clinical-and-clinical-investigation-devices-used-treatment-benign-prostatic-hyperplasia> . Accessed 20 March 2020.

14. Griffith JW. Self-report measurement of lower urinary tract symptoms: a commentary on the literature since 2011. Curr Urol Rep. 2012;13(6):420-6.

15. Djavan B. Lower urinary tract symptoms/benign prostatic hyperplasia: fast control of the patient's quality of life. Urology. 2003;62(3 Suppl 1):6-14.

16. O'leary MP. Validity of the "bother score" in the evaluation and treatment of symptomatic benign prostatic hyperplasia. Rev Urol. 2005;7(1):1-10.

17. Barry MJ, Williford WO, Chang Y, Machi M, Jones KM, Walker-Corkery E, et al. Benign prostatic hyperplasia specific health status measures in clinical research: how much change in the American Urological Association symptom index and the benign prostatic hyperplasia impact index is perceptible to patients? J Urol. 1995;154(5):1770-4.

18. Välitalo PAJ, van Dijk M, Krekels EHJ, Gibbins S, Simons SHP, Tibboel D, et al. Pain and distress caused by endotracheal suctioning in neonates is better quantified by behavioural than physiological items: a comparison based on item response theory modelling. Pain. 2016;157(8):1611-7.

19. Välitalo PA, Krekels EH, van Dijk M, Simons S, Tibboel D, Knibbe CA. Morphine pharmacodynamics in mechanically ventilated preterm neonates undergoing endotracheal suctioning. CPT Pharmacometrics Syst Pharmacol. 2017;6(4):239-48.

20. Chae D, Park K. An item response theory based integrated model of headache, nausea, photophobia, and phonophobia in migraine patients. J Pharmacokinet Pharmacodyn. 2018;45(5):721-31.

21. Lyauk YK, Jonker DM, Lund TM, Hooker AC, Karlsson MO. Item response theory modeling of the International Prostate Symptom Score in patients with lower urinary tract symptoms due to benign prostatic hyperplasia. AAPS J (submitted).

22. Welch G, Kawachi I, Barry MJ, Giovannucci E, Colditz GA, Willett WC. Distinction between symptoms of voiding and filling in benign prostatic hyperplasia: findings from the health professionals follow-up study. Urology. 1998;51(3):422-7.

23. Barry MJ, Williford WO, Fowler FJ, Jones KM, Lepor H. Filling and voiding symptoms in the American Urological 
Association symptom index: the value of their distinction in a veterans affairs randomized trial of medical therapy in men with a clinical diagnosis of benign prostatic hyperplasia. J Urol. 2000;164(5):1559-64.

24. Krekels E, Novakovic AM, Vermeulen AM, Friberg LE, Karlsson MO. Item response theory to quantify longitudinal placebo and paliperidone effects on PANSS scores in schizophrenia. CPT Pharmacometrics Syst Pharmacol. 2017;6(8):54351.

25. Gottipati G, Karlsson MO, Plan EL. Modeling a composite score in Parkinson's disease using item response theory. AAPS J. 2017;19(3):837-45.

26. Ueckert S. Modeling composite assessment data using item response theory. CPT Pharmacometrics Syst Pharmacol. 2018;7(4):205-18.

27. Schindler E, Friberg LE, Lum BL, Wang B, Quartino A, Li C, et al. A pharmacometric analysis of patient-reported outcomes in breast cancer patients through item response theory. Pharm Res. 2018;35(6):122.

28. Samejima F. Estimation of latent ability using a response pattern of graded scores. Psychometrika. 1969;34(1):1-97.

29. De Ayala RJ, Hertzog MA. The assessment of dimensionality for use in item response theory. Multivariate Behav Res. 1991;26(4):765-92.

30. Kaiser HF. The varimax criterion for analytic rotation in factor analysis. Psychometrika. 1958;23(3):187-200.

31. Muraki E, Carlson JE. Full-information factor analysis for polytomous item responses. 1995 [Internet]. Available from: https://journals.sagepub.com/doi/10.1177/014662169501900109. Accessed 21 Mar 2020.

32. Keizer RJ, Karlsson MO, Hooker A. Modeling and Simulation Workbench for NONMEM: Tutorial on Pirana, PsN, and Xpose. CPT Pharmacometrics Syst Pharmacol. 2013;2:e50.

33. Chalmers RP. mirt: a multidimensional item response theory package for the R environment. J Stat Softw. 2012;48(1):1-29.

34. Vong C, Bergstrand M, Nyberg J, Karlsson MO. Rapid sample size calculations for a defined likelihood ratio test-based power in mixed-effects models. AAPS J. 2012;14(2):176-86.

35. Becher E, Roehrborn CG, Siami P, Gagnier RP, Wilson TH, Montorsi F. The effects of dutasteride, tamsulosin, and the combination on storage and voiding in men with benign prostatic hyperplasia and prostatic enlargement: 2-year results from the combination of Avodart and Tamsulosin study. Prostate Cancer Prostatic Dis. 2009;12(4):369-74.

36. Montorsi F, Roehrborn C, Garcia-Penit J, Borre M, Roeleveld TA, Alimi J-C, et al. The effects of dutasteride or tamsulosin alone and in combination on storage and voiding symptoms in men with lower urinary tract symptoms (LUTS) and benign prostatic hyperplasia (BPH): 4-year data from the combination of Avodart and Tamsulosin (CombAT) study. BJU Int. 2011;107(9):1426-31.

37. Porst H, Oelke M, Goldfischer ER, Cox D, Watts S, Dey D, et al. Efficacy and safety of tadalafil $5 \mathrm{mg}$ once daily for lower urinary tract symptoms suggestive of benign prostatic hyperplasia: subgroup analyses of pooled data from 4 multinational, randomized, placebo-controlled clinical studies. Urology. 2013;82(3):667-73.

38. Barry MJ, Cantor A, Roehrborn CG, CAMUS Study Group. Relationships among participant international prostate symptom score, benign prostatic hyperplasia impact index changes and global ratings of change in a trial of phytotherapy in men with lower urinary tract symptoms. J Urol. 2013;189(3):987-92.

39. Brasure M, MacDonald R, Dahm P, Olson CM, Nelson VA, Fink HA, et al. Newer medications for lower urinary tract symptoms attributed to benign prostaic hyperplasia: a review [Internet]. Rockville (MD): Agency for Healthcare Research and Quality (US); 2016. (AHRQ Comparative Effectiveness Reviews). Available from: http://www.ncbi.nlm.nih.gov/books/ NBK368444/. Accessed 23 Mar 2020.

40. Bosch JL, Hop WC, Kirkels WJ, Schröder FH. The International Prostate Symptom Score in a community-based sample of men between 55 and 74 years of age: prevalence and correlation of symptoms with age, prostate volume, flow rate and residual urine volume. Br J Urol. 1995;75(5):622-30.

41. Sountoulides P, van Dijk MM, Wijkstra H, de la Rosette JJMCH, Michel MC. Role of voiding and storage symptoms for the quality of life before and after treatment in men with voiding dysfunction. World J Urol. 2010;28(1):3-8.

42. Engström G, Henningsohn L, Walker-Engström M-L, Leppert J. Impact on quality of life of different lower urinary tract symptoms in men measured by means of the SF 36 questionnaire. Scand J Urol Nephrol. 2006;40(6):485-94.

43. Coyne KS, Wein AJ, Tubaro A, Sexton CC, Thompson CL, Kopp ZS, et al. The burden of lower urinary tract symptoms: evaluating the effect of LUTS on health-related quality of life, anxiety and depression: EpiLUTS. BJU Int. 2009 Apr;103(Suppl 3):4-11.

44. Ikemoto I, Kiyota H, Suzuki Y, Oishi Y, Kishimoto K, Shimomura T, et al. Roles of BPH impact index in the evaluation of impaired urination in patients with BPH. Nippon Hinyokika Gakkai Zasshi. 2005;96(6):623-31.

45. Sympson JB. A model for testing with multidimensional items. In: Weiss DJ, editor. Proceedings of the 1977 computerized adaptive testing conference. Minneapolis: University of Minnesota; 1977 . p. 82-98.

46. International Conference on Harmonisation E9(R1) Addendum: Statistical principles for clinical trials - estimands and sensitivity analysis in clinical trials. 2020. https:// www.ema.europa.eu/en/documents/scientific-guideline/ich-e9-r1addendum-estimands-sensitivity-analysis-clinical-trials-guideline-statistical-principles_en.pdf. Accessed 11 March 2020.

47. Barry MJ, Fowler FJ, O'Leary MP, Bruskewitz RC, Holtgrewe HL, Mebust WK. Measuring disease-specific health status in men with benign prostatic hyperplasia. Measurement Committee of the American Urological Association. Med Care. 1995;33(4 Suppl):AS145-55.

48. de la Rosette JJ, Witjes WP, Schäfer W, Abrams P, Donovan JL, Peters TJ, et al. Relationships between lower urinary tract symptoms and bladder outlet obstruction: results from the ICS"BPH" study. Neurourol Urodyn. 1998;17(2):99-108.

49. Sandvik H, Espuna M, Hunskaar S. Validity of the incontinence severity index: comparison with pad-weighing tests. Int Urogynecol J Pelvic Floor Dysfunct. 2006 Sep;17(5):520-4.

50. Coyne KS, Barsdorf AI, Thompson, Ireland A, Milsom I, Chapple C, et al. Moving towards a comprehensive assessment of lower urinary tract symptoms (LUTS). Neurourol Urodyn. 2012 Apr;31(4):448-54.

51. Avery K, Donovan J, Peters TJ, Shaw C, Gotoh M, Abrams P. ICIQ: a brief and robust measure for evaluating the symptoms and impact of urinary incontinence. Neurourol Urodyn. 2004;23(4):322-30.

52. EuroQol Group. EuroQol-a new facility for the measurement of health-related quality of life. Health Policy. 1990 Dec;16(3):199-208.

53. Hayes M. Patterson D. Psychol Bull: Experimental development of the graphic rating method; 1921.

54. Yeung AWK, Wong NSM. The historical roots of visual analog scale in psychology as revealed by reference publication year spectroscopy. Front Hum Neurosci [Internet]. 2019; Accessed 21 Mar 2020. Available from: https://www.frontiersin.org/articles/ 10.3389/fnhum.2019.00086/full.

55. Idé T, Dhurandhar A. Supervised item response models for informative prediction. Knowl Inf Syst. 2017;51(1):235-57.

56. Goulooze SC, Ista E, van Dijk M, Hankemeier T, Tibboel D, Knibbe CAJ, et al. Supervised multidimensional item response theory modeling of pediatric iatrogenic withdrawal symptoms. CPT Pharmacometrics Syst Pharmacol. 2019;8(12):904-12.

Publisher's Note Springer Nature remains neutral with regard to jurisdictional claims in published maps and institutional affiliations. 